SYSTEMATIC REVIEW

\title{
EFFECTS OF PHYSIOTHERAPY INTERVENTIONS ON FALL, POSTURE AND QUALITY OF LIFE IN PARKINSON DISEASE
}

\begin{abstract}
BACKGROUND AND AIMS

Parkinson disease is the 2nd most common neurological disorder worldwide that is mainly associated with motor system. The role of non-pharmacological treatment in the management of fall, posture and improving quality of life is yet unclear therefore this review was conducted to evaluate the effects of physiotherapy interventions on fall, posture and quality of life in PD patients.
\end{abstract}

\section{DATABASES AND ELIGIBILITY CRITERIA}

A literature search was conducted through Google Scholar, PEDro, Cochrane Library, Med-line, CINAHL, Web of Science and PubMed included 18 randomized controlled trials evaluating physiotherapy interventions effects on fall, posture or QOL in PD patients that published in the year 2010 to onwards 2019 were included.

\section{RESULTS}

Methodological quality and risk of bias was assessed using the Cochrane tool for assessing risk of bias. The findings revealed that PT treatments like resistance training, balance exercises, exergaming and low-intensity trunk exercises are effectual in enhancing QOL and postural imbalance. However resistance strength training, fall education and gait training more effectively reduces fall.

\section{CONCLUSION}

Physiotherapy interventions play an essential role in the treatment of fall, postural imbalance and QOL. These interventions should be integrated in the treatment plan so that PD patients can achieve greater independence in their lives.

\section{KEYWORDS}

Rehabilitation, Parkinson's disease, fall, posture, quality of life, Parkinsonism

\author{
Hajra Ameer Shaikh \\ MPhil (Student) \\ Ziauddin College of Rehabilitation Sciences \\ hajraameer90@gmail.com \\ Sarah Masood \\ Senior Lecturer \\ Neuromusculoskeletal Rehabilitation \\ Ziauddin College of Rehabilitation Sciences \\ bahriacollege834@gmail.com
}

[Shaikh HA, Masood S. Effects of Physiotherapy Interventions on Fall, Posture and Quality of Life In Parkinson Disease-A systematic Review Pak.j.rehabil.2019;8(1)4-12] 


\section{INTRODUCTION}

Parkinson disease (PD) is a motor disease with an unknown etiology occurs due to the degeneration of neurons and receptors, subsequently lacking the dopamine'. It was listed as the 2 nd most wide spread neurological disorder, estimated to affect 6.5 million people that is expected to double in next $10-20$ years ${ }^{2}$. It was found that in 2015 , men are 50 percent more likely to develop PD than women whereas the overall risk for women appears to increase with age. The neuropsychiatric symptoms of PD may include depression, psychosis, apathy, impulse control disorders that are linked with the poor quality of life due to the progression of disease ${ }^{3-4}$. Despite, cognitive impairment in PD is of great significance in terms of therapeutic approaches in order to deal with motor deficits of disorder ${ }^{5}$. Multiple studies have revealed that exercise has been proven to be effective for the maintenanceof health and well-being in Parkinson's. More importantly it is shown to play a significant role in addressing secondary prevention based on strength, flexibility, functional independence as well as gait and balance respectively. For PD, exercises based on neuroprotection that typically lies on endurance and motor learning principles approaches that are found to be effective in early stages of the disease for the prevention of adverse consequences. However, management of PD is more likely to be effective if an individual diagnose it early in the development of disease. For this reason, an early identification is crucial in Parkinson's. However, limited evidence is available to determine the association of posture, cognition and fall risks in PD in-context to the anti-Parkinsonian medications that control the disease manifestation ${ }^{6-7}$.

Number of studies demonstrated that people with PD may experience changes in their posture during the course of disease that are subtle and pronounced that may leads to painful positions, postural instability and recurrent falling ${ }^{8-9}$. Despite of the consequences of falling still there is a lacking in identification in risk of fall prediction ${ }^{10-11}$. The pharmacological management of PD consisted of Levodopa (L-POPA), a dopamine replacement therapy introduced in 1960's that is the most effective drug till date. It is best at controlling the symptoms of the condition that particularly slower the movements and stiff, rigid body parts. However, due to its long term usage it has lost the efficacy and leads to the severe ${ }^{12}$. According to NICE guidelines patients of PD should be quickly referred to neurologist where they may prescribe Dopamine agonists to younger patients in order to avoid levodopa induced motor complications ${ }^{13}$. On the other hand, physiotherapy has long term effects in dealing the issues like muscular weakness, gait impairment and falling frequently. According to the recent studies, 4 weeks of gait training showed significant impact that may last for 3 to 12 months. Moreover, programs of sustained training may help in maintaining strength and posture as well as reduced the depression among PD patients. However studies based on modified therapies and psychological treatment is still unavailable ${ }^{14-15}$. It has been evident that risk of fall may be decreased with exercises targeting the potential factors ${ }^{16}$. Furthermore, resisted and balance training is found to be effective in reducing anxiety and thus improves the $Q \mathrm{OL}^{17-18}$. Therefore, this systemic review aims to provide an insight about the physiotherapy treatments effective in reducing risk of fall, improving posture and QOL in PD to identify the gap in therapeutic management of disease.

\section{METHODOLOGY}

This systematic Review was conducted in consideration of PRISMA (Preferred Reporting Items for Systematic Reviews and Meta-Analyses) recommendations ${ }^{19}$.

\section{Databases and Searching Strategy}

Six electronic databases that include PEDro, Google Scholar, Cochrane Library , Web of Science, PubMed and CINAHL were searched from 12th to 20th of May 2019 by using the MeSH terms for "Parkinson," "Parkinson's," and "Parkinson disease" together with "QOL," "fall," "posture," "physiotherapy," "rehabilitation,." Titles and/or abstracts were reviewed and researches not meeting inclusion criteria were excluded.

\section{Criteria for Eligibility of Studies}

All the randomized control trials with target population of PD, evaluated at least one of the following outcomes such as fall, posture or QOL published in 2010 to 2018 onwards with available English text were selected.

\section{Study Selection and Data Extraction}

Screening was executed on the basis of titles and/or abstracts that met the eligibility criteria were included in the systematic review based on risk of fall, QOL and posture correction by physiotherapy treatment. The data was extracted from selected studies included the effects of rehabilitation on $\mathrm{QOL}$, fall and posture in the management of PD with respect to intervention, frequency, duration, outcome measures.

\section{Risk of Bias}

Risk of bias was evaluated by using the Cochrane tool for assessing risk of bias 20-21 in random allocation, allocation concealment, blinding of participants and outcome assessment, incomplete outcome data, selective reporting and other bias. 


\section{RESULTS}

\section{Selection of Studies and Study Characteristics}

Total 103 records were analyzed from electronic data bases. After the initial screening 68 papers were excluded whereas after examining the inclusion criteria 35 number of trials were extracted to review in full-text, of which 18 RCTs conducted in between 2010 to 2018 were analyzed that involved a total of 1,185 PD patients and have investigated the effects of physiotherapy treatment on fall, postural and/or QOL in persons with PD. The outline of the screening strategy of the studies is summarized in Fig. 1.

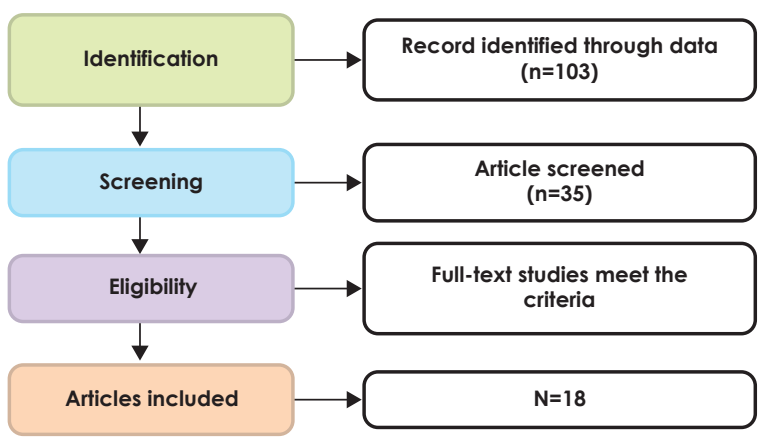

Figure-1: Shows inclusion of studies based on PRISMA guidelines

\section{Synthesized Findings}

Trials conducted by Sparrow et $\mathrm{al}^{22}$ and Shen et $\mathrm{al}^{23}$ reported that highly challenging balance program, gait training and technology-assisted balance training decreases fall rate i.e. up to $37 \%$ decline in fall rate in PD patients however previous studies $^{16,25,26}$ showed no significant reduction in fall through balance exercises although findings showed clinically significant improvements. Another study conducted in $2012^{24}$ reported home based progressive resistance strengthening exercises, fall education and movement strategies that reduce fall rate and cost effective PD patients. On the other hand, a study reported that exergaming interventions based on balance by using the kinetic sensor on balance training and postural stability both significantly improves posture in PD. that showed better results ${ }^{28}$. Similarly Laio et $\mathrm{al}^{31}$ concluded that balance exercises are effective in improving posture as compared with resistive training ${ }^{18}$. Furthermore a study in $2014^{29}$ reported that low intensity trunk exercise improve postural stability. Capecci et al. ${ }^{30}$ reported postural rehabilitation and Kinesio-taping equally effective in reducing postural disorders. A study by Morrone et al. ${ }^{27}$ concluded that perceptive rehabilitation is more effective in trunk posture alignment as compare to PT treatment in PD.

Despite, all studies use PDQ-39 as outcome measure. Interestingly all the trials reported improvement in the QOL by PT treatment i.e. resistance training, exergaming, functional rehabilitation, balance exercises, self-management rehabilitation, except study by Cruise et al. in 2011 who reported that moderate-to-high-intensity aerobic and anabolic exercise did not benefit QOL in PD. The details are showed in Table-1.

\begin{tabular}{|c|c|c|c|}
\hline Author, Year & $\begin{array}{l}\text { Sample } \\
\text { Size }(n)\end{array}$ & $\begin{array}{l}\text { Study } \\
\text { Design }\end{array}$ & Intervention \\
\hline Sparrow et al 2016 & 23 & RCT & $\begin{array}{l}\text { High - intensity balance exercises twice weekly for } \\
90 \text { minutes for the duration of } 3 \text { months }\end{array}$ \\
\hline Colleen et al 2015 & 231 & RCT & $\begin{array}{l}\text { Muscle strengthening and balance exercises } \\
\text { strength for the duration of } 6 \text { months }\end{array}$ \\
\hline Shen etal 2014 & 51 & RCT & $\begin{array}{l}\text { Technology assisted balance and gait training for } \\
3 \text { sessions/w eek and } 5 \text { session/weeks of self } \\
\text { supervised home base training for } 12 \text { months }\end{array}$ \\
\hline Morris et al 2012 & 180 & RCT & $\begin{array}{l}\text { Progressive resistance strength training, and fall } \\
\text { education for } 1 \mathrm{hr} / \text { week for the duration of } 12 \\
\text { months }\end{array}$ \\
\hline Goodwin et $a^{25} 2011$ & 130 & RCT & $\begin{array}{l}\text { balance and strengthening exercises for } 40 \\
\text { minutes for } 30 \text { weeks }\end{array}$ \\
\hline Colgrove et al 2010 & 13 & RCT & $\begin{array}{l}\text { lyengar Hatha yoga program was tailored to } \\
\text { improve strength, flexibility, body alignment, and } \\
\text { overall well - being for } 60 \text { mins session twice a } \\
\text { week for } 12 \text { weeks }\end{array}$ \\
\hline
\end{tabular}




\begin{tabular}{|c|c|c|c|}
\hline Morrone etal 2016 & 20 & RCT & $\begin{array}{l}\text { Perceptive Re -habilitation, stretching, } \\
\text { coordination and balance exercises for } 45 \\
\text { minutes, } 3 \text { days/week for } 1 \text { month }\end{array}$ \\
\hline Meng-Che-Shihet al 2016 & 20 & RCT & Balance based exergaming group for 8 weeks \\
\hline Christian et al $^{18} 2015$ & 32 & RCT & Resistance and balance training for 12 weeks \\
\hline Hubble et al 2914 & 45 & RCT & $\begin{array}{l}\text { Low intensity and progressive trunk exercise once } \\
\text { or thrice/week for } 12 \text { weeks }\end{array}$ \\
\hline Capecciet al 2014 & 20 & RCT & $\begin{array}{l}\text { Proprioceptive and tactile stimulation, combined } \\
\text { with stretching and postural reeducation for } 40 \\
\text { minutes, } 3 \text { days/week for } 4 \text { weeks }\end{array}$ \\
\hline Laio et al 2014 & 36 & RCT & $\begin{array}{l}\text { VR based Wii Fit Training for } 45 \text { mins/day, } 2 \\
\text { days per week for } 6 \text { week s }\end{array}$ \\
\hline Ferriera et al ${ }^{17} 2018$ & 35 & RCT & $\begin{array}{l}\text { Resistance training program for } 30 \text { to } 40 \text { min/day } \\
\text { for } 24 \text { weeks }\end{array}$ \\
\hline Ribas etal 2017 & 20 & RCT & Exergaming for 12 weeks \\
\hline Cholewa et al 2014 & 51 & RCT & $\begin{array}{l}\text { Rehabilitation for } 60 \text { minutes, twice/week for } 15 \\
\text { weeks }\end{array}$ \\
\hline Cholewa et al 2013 & 70 & RCT & $\begin{array}{l}\text { Rehabilitation for } 60 \text { minutes, twice/week for } \\
12 \text { weeks }\end{array}$ \\
\hline Cruise et al 2011 & 28 & RCT & $\begin{array}{l}\text { Moderate-to-high -intensity anabolic and aerobic } \\
\text { exercise, } 1 \text { hr per day for } 12 \text { weeks }\end{array}$ \\
\hline Yen et al ${ }^{36} 2011$ & 28 & RCT & $\begin{array}{l}\text { Customized Balance Board Therapy for } 30 \\
\text { mins/day, } 2 \text { days per week for } 12 \text { weeks }\end{array}$ \\
\hline
\end{tabular}

Consecutively, the effects of physiotherapy interventions on fall, posture and quality of life in PD is inconclusive in the studies included. However significant improvement was reported in intervention like resistance training, balance exercises, exergaming and low-intensity trunk exercises in enhancing QOL and posture instability. Whereas resistance strength training, gait training and fall education more effectively reduce risk of fall in PD.

Quality Appraisal and Risk of Bias within studies

All trials had low risk of bias in random allocation while only one study showed low risk of bias in all the measures ${ }^{17}$. In majority of the trials high risk of bias regarding blinding of outcome assessment was found ${ }^{16,23,24,26,28,18,29,30,32-35}$ whereas in $50 \%$ of the trials blinding of participants had low risk of bias $16,24,28,29,30,31,17,35$ and 36 . The risk of bias could not be ensured from the method defined for other bias from some studies $23,26,32,33 \& 36$. The section that was least defined, and therefore possessed the upmost risk of biaswas allocation concealment $22,16,23,25,26,27,28,18,30,32,33,34,35$ as demonstrated in Table-2. 


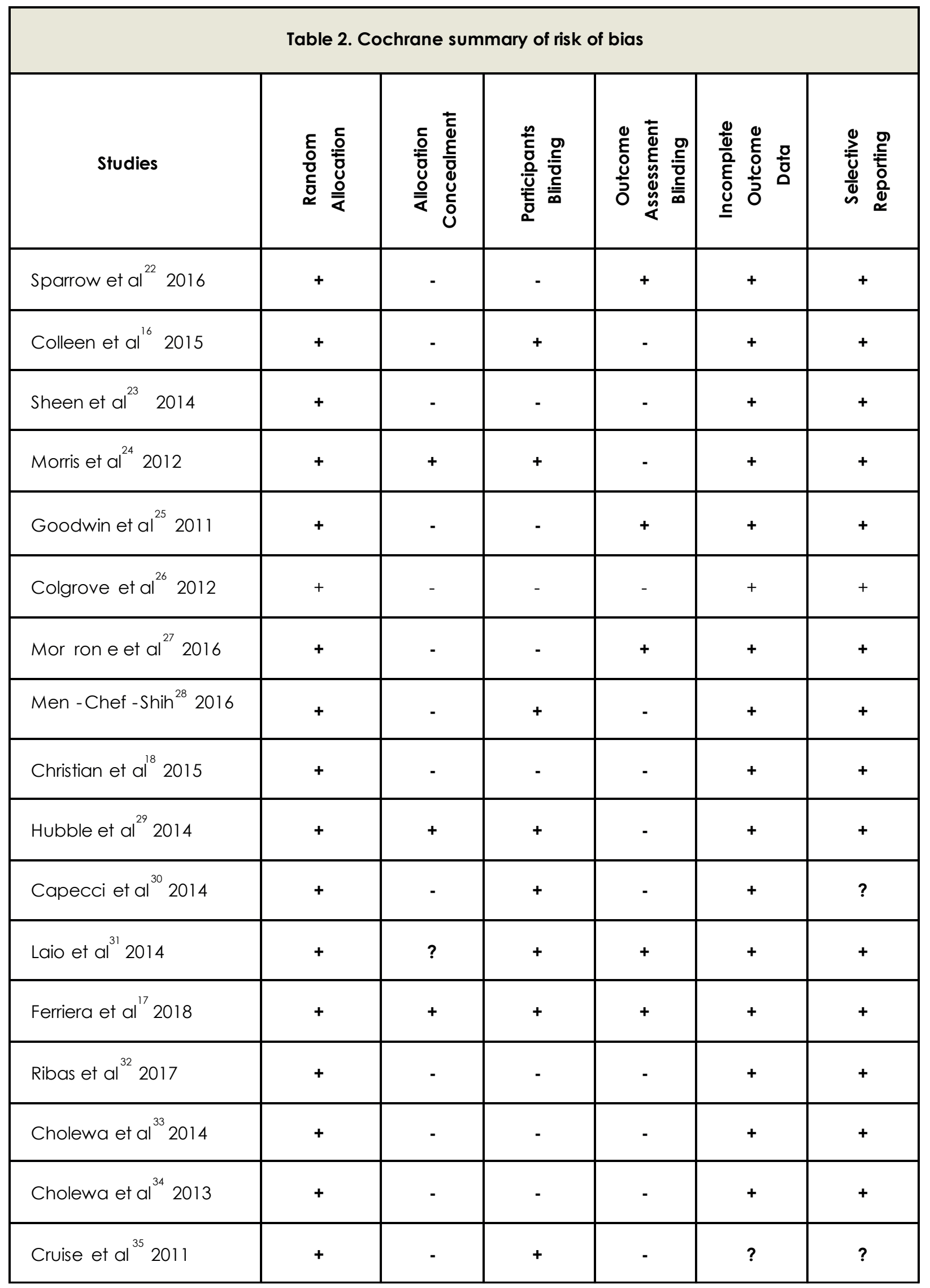




\begin{tabular}{|l|l|l|l|l|l|l|}
\hline Yen et al $^{36} 2011$ & + & + & + & + & + & + \\
\hline
\end{tabular}

\section{DISCUSSION}

TThis review endorsed the evidences collected from the numerous trials accessing the variety of physiotherapy methods to evaluate the effects of physiotherapy in Parkinson's disease. Moreover, it has been enlightened the enormous range of physiotherapy modalities and manual methods being used in the management of PD. However, there is a scarcity of studies with relatively small sample size with disparity and heterogeneity of certain variables and outcome measures therefore only 18 randomized controlled trials were included to addresses fall, posture and QoL as variables of interest. It has been observed that sample sizes of various studies were limited although the PT interventions were found to be significantly improving the QoL among the groups. In addition, considering patients with PD are at high risk of postural instability and stiffness therefore more studies are required for the assessment as PT interventions drastically improves postural complications and prevents it from getting worse with the progression of PD. Out of all studies related to fall only four could justify the massive significance of PT over reducing the rate of fall in PD. Shen et $\mathrm{al}^{23}$. explained that technology assisted balance training was found more efficient than strengthening exercise to reduce falls in PD whereas Colgrove et al26 showed that progressive lower limb strength decreases falling by $7 \%$ but still this difference was not significant enough. In this regard, Yitayeh et al37 gave a systemic review proving that PT intervention like balance training combined with muscle strengthening decrease the incidence of fall which shows that study ${ }^{23}$ was not justified to prove the efficacy of management.

As, one of the most prominent sign in PD is postural instability thus, the postural coping intervention studies as Morrone et $\mathrm{Al}^{27}$. demonstrated that kyphotic angle in perceptive rehabilitation more effectively reduces kyphosis whereas Laio et al31 showed that balancing training in PD showed significant improvement in postural stability. Meng Che Shih et al. ${ }^{28}$ also demonstrated about the posture maintenance but with varied intervention called balance based exergaming. However, the findings of Yuki kawami et $\mathrm{al}^{38}$ showed improvement in stooped posture and lumber lordosis in PD those who had PT based rehabilitation. Despite, Studies $31,30,28,18,29$ successfully only explained the effectiveness of exercise regime but Jamil Vivas et al.39 talked about an innovative intervention called aquatic therapy in combination with PT and the results were positive on large scale when we talk about postural stability and to overcome body stiffness. One of the important key variables, QoL is affected in PD, in this regard Ribas et $\mathrm{a}^{32}$ demonstrated that exergaming is effective to significantly improve QOL but the long term. Similarly study of Joanna Cholewa et $\mathrm{al}^{33}$ demonstrated the effectiveness of a regular functional movement rehab in PD that may reduce the escalation of symptoms thereby enhancing QOL. Cholewa et $\mathrm{al}^{34}$. further confirmed the effectiveness of PT on QOL in PD by showing mean score increased by $9.69 \%$. However Docks et $\mathrm{al}^{40}$ added technology of virtual reality as an innovation in concept of rehabilitation. This tool in combination with PT to produce maximum effects on QOL but still high quality studies required to confirm these findings. On the contrary, Cruise et $\mathrm{Al}^{35}$ demonstrated that aerobic and anaerobic exercises are not beneficial in improving QOL in PD. Further studies ${ }^{24}$ endorsed the view of home based program that can produce similar effects to improve conditions in PD. A similar study carried out by Shenkman et $\mathrm{al}^{41}$, lun et $\mathrm{al}^{42}$ andAshburn et $\mathrm{al}{ }^{43}$ that highlighted the same fact that self-supervised program or personalized home based exercise prescribed by Physiotherapist could be an option to cope up with the symptoms of PD at home. On the contrary, progressive resisted training exercise Poliak et $\mathrm{a}^{44}$ proposed a study which explained the great influence of gym training over the QOL in PD as it improves illness perceptions and enables the participants to socialize and boost confidence. Therefore, numbers of clinical trials are required to demonstrate the importance of the application of PT in treating issues like fall, posture and QOL in PD. Moreover, interventions in transition care settingare also required that may improve the independence and functioning of the patients in order to delay their adverse symptoms based on the progression of disease. Furthermore, more goal-oriented and therapy-focused services to older people after a hospital stay that may include low-intensity therapy, occupational therapy, social work, nursing support as well as personal care might be more significant. Therefore, more quantitative and qualitative data suggests better outcomes in older patients with family participation to assist physiotherapy care in PD management.

\section{Strengths}

To the best of author's knowledge, this review is the first to evaluate the effects of physiotherapy and/or rehabilitation on fall, posture and QOL in PD. More- 
over, it will contribute to identify gaps in the existing and current evidence that is important to be addressed.

\section{Limitations}

Majority of the trials in this systematic review were of small sample size and short follow-up period. There is a higher risk of bias due to allocation concealment and blinding. The methodological quality of some studies was inadequate.

\section{Future Recommendations}

Further high impact researches are required for the better understanding of the fact that what type of PT interventions is impactful to the large group of representatives of PD. Such researches must utilize accurate outcome measures to analyze the changes in posture, no of falls and QOL of PD and must consider the allocation concealment and blinding protocol to remove the risks of biasness. Furthermore long term effect of PT is needed to evaluate.

\section{CONCLUSION}

The available evidence concluded that rehabilitation plays a vital role in managing fall, postural imbalance and QOL. PT treatments like resistance training, balance exercises, exergaming, low-intensity trunk exercises and self-management rehabilitation are efficient in enhancing QOL and posture instability. However resistance strength training, gait training and fall education are more effective in reducing rate of fall as compare to balance exercises in PD. These PT treatments strategies should be integrated in the treatment plan together with pharmacological treatment so that individuals with PD can become independent to a greater extent.

\section{Conflict of Interest}

The authors declared no conflicting interests regarding publication or authorship of this systematic review.

\section{Funding}

No any financial support was received by authors for this systematic review.

\section{Acknowledgement}

The authors are pleased to acknowledge Miss Sumaira Imran Farooqui (Principal) and Miss Amna Aamir Khan (Assistant Professor) from Ziauddin college of Rehabilitation Sciences with gratitude for giving us the platform.

\section{REFERENCES}

[1] Corti O, Lesage S, Brice A. What genetics tells us about the causes and mechanisms of Parkinson's disease? Physiological reviews. $2011 ; 91(4): 1161$ $-218$.
[2] Cilingir O, Ozkan S, Aras BD, Erzurumluoglu E, Kutlay $O$, Akinci $M$, Emir B, Afagh A, Artan S. Association of functional RAGE gene polymorphisms with Parkinson's disease in a Turkish cohort. Biomedical Research. 2017;28(19):8454-60.

[3] Katunina E, Titova N. The epidemiology of nonmotor symptoms in Parkinson's disease (cohort and other studies). InInternational review of neurobiology 2017 (Vol. 133, pp. 91-110). Academic Press.

[4] Aarsland D, Kramberger MG. Neuropsychiatric symptoms in Parkinson's disease. JPD. 2015 ;5(3):659-67.

[5] Barcelos LB, Saad F, Giacominelli C, Saba RA, de Carvalho Aguiar PM, Silva SM, Borges V, Bertolucci $\mathrm{PH}$, Ferraz HB. Neuropsychological and clinical heterogeneity of cognitive impairment in patients with multiple system atrophy. Clinical neurology and neurosurgery. 2018 Jan 1;164:121-6.

[6] Plotnik M, Giladi N, Dagan Y, Hausdorff JM. Postural instability and fall risk in Parkinson's disease: impaired dual tasking, pacing, and bilateral coordination of gait during the "ON" medication state. Experimental brain research. $2011 ; 210(3-4): 529-38$.

[7] De Virgilio A, Greco A, Fabbrini G, Inghilleri $M$, Rizzo MI, Gallo A, Conte M, Rosato C, Appiani MC, de Vincentiis M. Parkinson's disease: autoimmunity and neuroinflammation. Autoimmunity reviews. 2016 Oct 1;15(10):1005-11. Worth PF. How to treat Parkinson's disease in 2013. Clinical medicine. 2013 13(1):93-6.

[8] Mak MK, Wong-YU IS, Shen X, Chung CL. Long-term effects of exercise and physical therapy in people with Parkinson disease. Nature Reviews Neurology. 2017;13(11):689.

[9] Fan JY, Chang BL, WU YR. Relationships among depression, anxiety, sleep, and quality of life in patients with Parkinson's disease in Taiwan. Parkinson's Disease. 2016;2016.

[10] Santos-García D, de la Fuente-Fernández R. Impact of non-motor symptoms on health-related and perceived quality of life in Parkinson's disease. J Neurol Sci.2013;332(1-2):136-40.

[1 1] Mancini M, Horak FB, Zampieri C, Carlson-Kuhta P, Nutt JG, Chiari L. Trunk accelerometry reveals postural instability in untreated Parkinson's disease. Parkinsonism\& related disorders. $2011 ; 17(7)$ :557-62.

[12] Grimbergen YA, Schrag A, Mazibrada G, Borm GF, Bloem BR. Impact of falls and fear of falling on health-related quality of life in patients with Parkinson's disease. Journal of Parkinson's disease. 2013;3(3):409-13.

[13] Beghi E, Gervasoni E, Pupillo E, Bianchi E, Montesano A, Aprile I, Agostini M, Rovaris $M$, Cattaneo D, lacobone G, Jonsdottir J. Prediction of falls in subjects suffering from Parkinson disease, multiple sclerosis, and stroke. Archives of physical medicine and rehabilitation. $2018 ; 99(4): 641-51$.

[14] Aarsland D, Bronnick K, Williams-Gray C, Weintraub D, Marder K, Kulisevsky J, Burn D, Barone P, Pagonabarraga J, Allcock L, Santangelo G. Mild 
cognitive impairment in Parkinson disease: a multicenter pooled analysis. Neurology. $21 ; 75(12): 1062-9$.

[15] Canning CG, Sherrington C, Lord SR, Close JC, Heritier S, Heller GZ, Howard K, Allen NE, Latt MD, Murray SM, O'Rourke SD. Exercise for falls prevention in Parkinson disease: a randomized controlled trial. Neurology. 2015;84(3):304-12.

[16] Ferreira RM, Alves WM, Lima TA, Alves TG, Alves Filho PA, Pimentel CP, Sousa EC, Cortinhas-Alves EA. The effect of resistance training on the anxiety symptoms and quality of life in elderly people with Parkinson's disease: a randomized controlled trial. Arquivos de neuro-psiquiatria. 2018;76(8):499-506. [17] Schlenstedt C, Paschen S, Kruse A, Raethjen J, Weisser B, Deuschl G. Resistance versus balance training to improve postural control in Parkinson's disease: a randomized rater blinded controlled study. PLoS One. 2015;10(10):e0140584.

[18] Moher D, Liberati A, Tetzlaff J, Altman DG. Preferred reporting items for systematic reviews and meta-analyses: the PRISMA statement. Annals of internal medicine. 2009;151 (4):264-9.

[19] Cusso ME, Donald KJ, Khoo TK. The impact of physical activity on non-motor symptoms in Parkinson's disease: a systematic review. Frontiers in medicine. 2016 3:35.

[20] Higgins JP, Altman DG, Gøtzsche PC, Jüni $P$, Moher D, Oxman AD, Savović J, Schulz KF, Weeks L, Sterne JA. The Cochrane Collaboration's tool for assessing risk of bias in randomised trials. Bmj. $2011 ; 343:$ d5928.

[21] Sparrow D, DeAngelis TR, Hendron K, Thomas CA, Saint-Hilaire $M$, Ellis T. Highly challenging balance program reduces fall rate in Parkinson disease. Journal of neurologic physical therapy: JNPT. 2016:40(1):24.

[22] Shen X, Mak MK. Technology-assisted balance and gait training reduces falls in patients with Parkinson's disease: a randomized controlled trial with 12-month follow-up. Neuro rehabilitation and neural repair. 2015;29(2):103-11.

[23] Morris ME, Martin C, McGinley JL, Huxham FE, Menz HB, Taylor NF, Danoudis M, Watts JJ, Soh SE, Evans $\mathrm{AH}$, Horne M. Protocol for a home-based integrated physical therapy program to reduce falls and improve mobility in people with Parkinson's disease. BMC neurology. $2012 ; 12(1): 54$.

[24] Goodwin VA, Richards SH, Henley W, Ewings P, Taylor AH, Campbell JL. An exercise intervention to prevent falls in people with Parkinson's disease: a pragmatic randomised controlled trial. J Neurol Neurosurg Psychiatry. 2011:82(11):1232-8.

[25] Yang WC, Wang HK, WU RM, Lo CS, Lin KH. Home-based virtual reality balance training and conventional balance training in Parkinson's disease: A randomized controlled trial. Journal of the Formosan Medical Association. 2016 ;1 15(9):734-43.

[26] Colgrove YS, Sharma N, Kluding P, Potter D, Imming K, VandeHoef J. Effect of yoga on motor function in people with Parkinson's disease: a randomized, controlled pilot study. J Yoga Phys Ther. 2012;2(2):112.

[27] Shih MC, Wang RY, Cheng SJ, Yang YR. Effects of a balance-based exergaming intervention using the Kinect sensor on posture stability in individuals with Parkinson's disease: a single-blinded randomized controlled trial. Journal of neuroengineering and rehabilitation. 2016;13(1):78. [28] Hubble RP, Naughton GA, Silburn PA, Cole MH. Trunk muscle exercises as a means of improving postural stability in people with Parkinson's disease: a protocol for a randomised controlled trial. BMJ open. 2014;4(12):e006095.

[29] Capecci M, Serpicelli C, Fiorentini L, Censi G, Ferretti M, Orni C, Renzi R, Provinciali L, Ceravolo MG. Postural rehabilitation and Kinesio taping for axial postural disorders in Parkinson's disease. Archives of physical medicine and rehabilitation. 2014:95(6):1067-75.

[30] Shih MC, Wang RY, Cheng SJ, Yang YR. Effects of a balance-based exergaming intervention using the Kinect sensor on posture stability in individuals with Parkinson's disease: a single-blinded randomized controlled trial. Journal of neuroengineering and rehabilitation. 2016 Dec;13(1):78.

[31] Liao Y, Yang YR, Wang RY. VR-Based Training Using Wii Fit Improve Obstacle Crossing Performance And Dynamic Balance In Patients With Parkinson Disease.2014.

[32] Cholewa J, Gorzkowska A, Szepelawy M, Nawrocka A, Cholewa J. Influence of functional movement rehabilitation on quality of life in people with Parkinson's disease. Journal of physical therapy science. 2014;26(9):1329-31.

[33] Cholewa J, Boczarska-Jedynak M, Opala G. Influence of physiotherapy on severity of motor symptoms and quality of life in patients with Parkinson disease. Neurologia i neurochirurgia polska. 2013;47(3):256-62.

[34] Cruise KE, Bucks RS, Loftus AM, Newton RU, Pegoraro R, Thomas MG. Exercise and Parkinson's: benefits for cognition and quality of life. Acta Neurologica Scandinavica. $2011 ; 123(1): 13-9$.

[35] Kessler D, Liddy C. Self-management support programs for persons with Parkinson's disease: An integrative review. Patient education and counseling. 2017 Oct 1;100(10):1787-95.

[36] Yen CY, Lin KH, Hu MH, Wu RM, Lu TW, Lin CH. Effects of virtual reality-augmented balance training on sensory organization and attentional demand for postural control in people with parkinson disease: a randomized controlled trial. Phys Ther. 2011 Jun 1;91(6):862-74.

[37] Kawami Y, Marumoto K, Shiomi Y, Okinishi M, Kozuki T, Oyabu H, Yokoyama K, Nikaido Y, Akisue T. The effect of comprehensive physiotherapy-based rehabilitation on stooped posture in Parkinson's disease. J Phys Ther Sci. 2018;30(12):1440-5.

[38] Ahlskog JE. Aerobic exercise: evidence for a direct brain effect to slow Parkinson disease progression. InMayo Clinic Proceedings 2018 (Vol. 
93, No. 3, pp. 360-372). Elsevier.

[39] Harris DM, Rantalainen T, Muthalib M, Johnson L, Duckham RL, Smith ST, Daly RM, Teo WP. Concurrent exergaming and transcranial direct current stimulation to improve balance in people with Parkinson's disease: study protocol for a randomised controlled trial. Trials. 2018 Dec;19(1):387.

[40] Poliakoff E, Galpin AJ, McDonald K, Kellett M, Dick JP, Hayes S, Wearden AJ. The effect of gym training on multiple outcomes in Parkinson's disease: a pilot randomised waiting-listcontrolled trial. NeuroRehabilitation. 2013;32(1):125-34.

[41] Gondim IT, Lins CC, Asano NM, Asano AG, Cabral ED, Coriolano MD. Individualized guidance and telephone monitoring in a self-supervised home-based physiotherapeutic program in Parkinson. Fisioterapia em Movimento. 2017 ;30(3):559-68.

[42] Vivas J, Arias P, Cudeiro J. Aquatic therapy versus conventional land-based therapy for Parkinson's disease: an open-label pilot study. Archives of physical medicine and rehabilitation. $2011 ; 92(8): 1202-10$

[43] Dockx K, Bekkers EM, Van den Bergh V, Ginis P, Rochester L, Hausdorff JM, Mirelman A, Nieuwboer A. Virtual reality for rehabilitation in Parkinson's disease. Cochrane Database of Systematic Reviews. 2016(12) 